Article

\title{
Optimal Coordination of Wind Power and Pumped Hydro Energy Storage
}

\author{
Hussein M. K. Al-Masri ${ }^{1, *}$, Ayman Al-Quraan ${ }^{1}$, Ahmad AbuElrub ${ }^{2}\left(\mathbb{D}\right.$ and Mehrdad Ehsani ${ }^{3}$ \\ 1 Department of Electrical Power Engineering, Yarmouk University, Irbid 21163, Jordan; aymanqran@yu.edu.jo \\ 2 Department of Electrical Engineering, Jordan University of Science and Technology, Irbid 22110, Jordan; \\ amabuelrub@just.edu.jo \\ 3 Department of Electrical and Computer Engineering, Texas A\&M University, College Station, \\ TX 77843, USA; ehsani@ece.tamu.edu \\ * Correspondence: h.almasri@yu.edu.jo; Tel.: +962-721-1111-4658
}

Received: 29 September 2019; Accepted: 13 November 2019; Published: 19 November 2019

check for updates

\begin{abstract}
A study combining wind power with pumped hydro energy storage for the Jordanian utility grid is presented. Three solvers of the Matlab optimization toolbox are used to find the optimal solution for the cost of energy in a combined on-grid system. Genetic algorithm, simulated annealing (SA), and pattern search (PS) solvers are used to find the optimal solution. The GA solution of $0.0955388 \$ / \mathrm{kWh}$ is economically feasible. This is $28.7 \%$ lower than the electricity purchased from the conventional utility grid. The discounted payback period to recover the total cost is 10.271 years. The suggested configuration is shown to be feasible by comparing it to real measurements for this case and a previous wind-only case. It is shown that the indicators of the optimal solution are improved. For instance, carbon dioxide emissions $\left(\mathrm{E}_{\mathrm{CO} 2}\right)$ and conventional grid energy purchases are reduced by $24.69 \%$ and $24.68 \%$, respectively. Moreover, it is shown that the benefits of adding hydro storage, combined with increasing the number of wind turbine units, reduces the cost of energy of renewables $\left(\mathrm{COE}_{\text {Renewables}}\right)$. Therefore, combining hydro storage with wind power is economically, environmentally, and technically a more efficient alternative to the conventional power generation.
\end{abstract}

Keywords: pumped hydro storage; wind farm; simulated annealing; genetic algorithm; pattern search; Matlab optimization toolbox; economic and environment feasibility

\section{Introduction}

Hydro and wind powers are promising renewables. However, due to the stochastic nature of the wind power, it is more efficient and reliable to combine it with another suitable energy system to provide a stable operation for large utility grid systems. Pumped hydro storage (PHS) is a suitable energy storage system that can be hybridized with wind power in order to overcome its variability and provide real-time load following. Hydro power makes up around 19\% of electrical power generated worldwide [1]. It is one of the oldest methods of renewable energy generation [2]. Hydropower originates from the sun, as its water cycle is driven by solar radiation. Approximately $22 \%$ of incoming solar energy is captured to form precipitation, which is the source of hydropower [3]. Hydropower stations can be categorized based on their output power. They are classified as small, mini, or micro types when the maximum output power is $15 \mathrm{MW}, 1 \mathrm{MW}$ and $100 \mathrm{~kW}$, respectively [4]. In this paper, the maximum output of the PHS exceeds the small type, therefore, a large type is added to the aforementioned category.

PHS plants are mainly used to serve demand during the peak load hours [3]. When wind generation exceeds demand, excess power can be stored by pumping water into the upper reservoir of the PHS system. Conversely, when the load exceeds the wind generation, the stored hydro energy can 
be used to supply the power deficit. In fact, PHS plants are considered to be one of the best utility-scale energy storage solutions due to their ability to supply power in just one to three minutes [3].

In the published literature, the operation of the grid-connected PHS, combined with wind power, has been extensively investigated. In [5], the authors suggested using pumped hydro storage as an operating reserve ancillary service in order to mitigate the problems related to wind farm integration with the grid. A probabilistic unit commitment using Lagrange relaxation was suggested to find the optimal scheduling of the thermal generators when wind power was integrated into the system while considering the uncertainty of the wind speed. It was found that pumped hydro storage could be effectively employed to reduce operating and flying reserve costs. In [6], PHS application in combination with a wind farm to increase profit in electricity markets was investigated. The results showed that the revenue was a function of the type of hydro storage used and market characteristics. The revenue increased by up to $11 \%$ by employing PHS. The authors in [7] proposed a deterministic, dynamic programming, long-term generation expansion model to find the optimal generation mix, total system cost, and total carbon dioxide emissions of a PHS system connected to a wind farm. It was found that in order to gain financial benefit from building the capital-intensive PHS, the exogenous market costs had to be very strong. In [8], a novel coordination strategy of a wind farm combined with PHS for a faster, reliable self-healing process in the grid restoration phase was proposed. The problem was formulated as a two-stage adaptive robust optimization and solved using the column-and-constraint generation (C\&CG) decomposition algorithm. The results proved that the PHS could increase system reliability and reduce wind power curtailment. A combinatorial planning model in order to maximize wind power utilization and reduce wind energy curtailment was studied in [9]. A posterior multi-objective (MO) optimization approach was proposed to deal with wind energy curtailment cost and the total social cost. The obtained results introduced an optimization approach capability and efficiency regarding the planning of renewable-based power systems. In [10], a sizing method for a wind-hydro system in the Canary Islands was proposed and its economic benefits for the island's electrical system were investigated. The contribution of this wind-hydro system to satisfying electricity demand was $29 \%$ higher than wind-only, and the electrical energy generation cost was reduced by $7.68 \mathrm{M} € /$ year. In [11], the authors presented an improved probabilistic production simulation method to facilitate the cost-benefit analysis of PHS. A case study on the IEEERTS79 system, which was used to demonstrate the effectiveness of the proposed simulation method, helped the industry move toward high penetration of the integrated wind energy power system.

In order for sustainable power generation to become universally adopted so that its planetary benefits are realized, the economic and technical designs of these power plants must be locally appropriate and optimal. This paper addresses this fundamental challenge for design engineers and managerial decision-makers.

The scientific/technical problem that is addressed and solved in this case study is as follows. In order to solve the global warming and cost of energy problems contributed to by electric power generation, local renewable resources must be utilized, combined, and optimized in their overall system design. This paper addresses these technical problems in a case study of combining wind and hydro power generation in Jordan as a specific location. In addition, this paper investigates the financial, environmental, and technical feasibility of wind farming and pumped hydro energy storage in an oil-importing country to reduce the energy-producing burden. Three heuristic optimization techniques are used from the Matlab optimization toolbox to verify the system design. Results show that the proposed system may be notably beneficial for Jordan. The same methodology can be applied in countries where this is relevant, such as Panama, a country which one of the authors visited for this purpose.

The fundamental problem of global sustainable energy production is the optimal use of locally specific renewable energy sources, such as wind and hydro energy resources, as laid out in this paper. In other words, this global problem must be solved locally everywhere. This is an engineering design optimization, which usually requires hybrid power plants. This paper presents a detailed case study 
of how this engineering problem is solved. In the process, it also sheds light on our concept of local solutions to a global problem. This important concept is often lost on countries and companies that attempt to build sustainable power generation projects.

In this paper, the Matlab optimization toolbox was used to find the optimal solution in terms of technical, environmental, and economic considerations. Moreover, genetic algorithm (GA), simulated annealing (SA), and pattern search (PS) techniques were used from the above toolbox to solve the problem described in this paper. Furthermore, it was shown that the objective function, cost of energy, of the on-grid, which was penetrated by the hydro-wind system ( $\left.\mathrm{COE}_{\mathrm{PS}}\right)$ was optimally minimized. The economically feasible solution was considered to find detailed solutions. This work aims to help decision-makers find the best technical solutions before actual implementation of the proposed energy configuration.

\section{Description of the Proposed System}

This paper discusses the combination of a wind and hydropower system (See Figure 1), which is integrated with the distribution grid in the country of Jordan, as a case study in an oil-importing country.

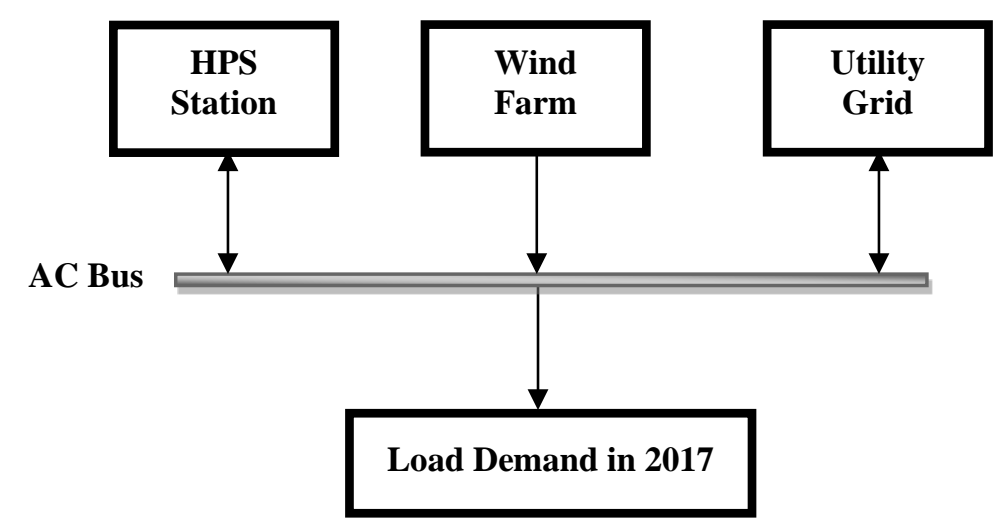

Figure 1. On-grid hydro-wind energy schematic.

The location was the same as one investigated in [12], where an on-grid wind power system was studied in Aqaba, Jordan. However, in this paper, an on-grid wind farm combined with a PHS station was investigated. Therefore, some data are the same, while others are updated for this more up-to-date study. The location was considered to be geographically suitable to construct a PHS station.

Artificial intelligence techniques (GA, SA, and PS) provided by the Matlab optimization toolbox were used to find the optimal solution of the objective function ( $\left.\mathrm{COE}_{\mathrm{PS}}\right)$. Then, based on the best fitness, many indicating corresponding functions were computed, such as the wind and hydro fraction $\left(\mathrm{WH}_{\mathrm{f}}\right)$, grid purchases, the footprint of the renewables, and carbon dioxide emissions $\left(\mathrm{E}_{\mathrm{CO} 2}\right)$. This procedure aimed to help design engineers replicate the same criteria to find optimal solutions for other system configurations to be adopted based on these technical studies and negotiations between electric utilities and investors. Economic, technical, and environmental feasibility impacts were also studied.

\subsection{PHS Station Data}

The information that was specified for the pumped hydro storage plant to be accurately modeled is shown in Table 1. First, the roundtrip efficiency referred to the ratio of the energy out to the energy in over a period of time [13]. It is difficult to separately measure the charging and discharging energies, therefore, manufacturers usually determine the round-trip efficiency and consider it to be the charging efficiency by assuming 100\% discharging efficiency. Many authors have discussed this issue in the case of battery systems. Thus, the charging efficiency was set to be equal to the round-trip efficiency, and the discharging efficiency was assumed be in agreement in $[14,15]$. 
Table 1. Values of parameters used for the pumped hydro storage (PHS) station.

\begin{tabular}{ccc}
\hline Parameter & Unit & Value \\
\hline Lifetime & Years & $50[16]$ \\
Usable state of charge [1] & $\%$ & 85 \\
Roundtrip efficiency $(\zeta)$ & $\%$ & $85[17]$ \\
Capital cost & $\$ / \mathrm{kW}$ & 1651.04 \\
Operation and maintenance cost (OMC) & $(\% /$ Year of capital cost (CC)) & 1.5 \\
Gross head & $\mathrm{m}$ & 50 \\
Mean water depth & $\mathrm{m}$ & 15 \\
\hline
\end{tabular}

Second, the usable state of charge (SOC) [1] referred to the ratio of the usable energy that was taken to the total energy of the PHS. In other words, the usable SOC was the energy left in the upper reservoir compared with the amount of energy in a full reservoir. This gave an indication into how long the PHS station could provide energy before a refill. In this study, it was assumed that a minimum stored energy should remain, and this value was the complement of the usable SOC. The usable SOC was assumed to be the same as the round-trip efficiency. Third, an initial PHS stored energy in the upper reservoir was assumed [18]. The aforementioned parameters helped to determine the PHS power generation capacity in $\mathrm{kW}$, which could be used to supply the load as needed. This capacity value was sized using the GA, SA, and PS of the Matlab optimization toolbox. The capital cost of the PHS had an average value of $1651.04 \$ / \mathrm{kW}$ [16]. The operation and maintenance costs (OMC) were taken as percentages of the capital cost (CC) [16]. Table 1 shows the values that were assumed and considered for the PHS plant. These plant data were used to compute the hourly energy generated. There was an approximate ratio of ten between the rated power (in $\mathrm{kW}$ ) and energy (in $\mathrm{kWh}$ ) of the PHS station, as stated in [19].

\subsection{Wind Speed and Probability Distribution Function}

Wind speed can change rapidly in any region. Its variation depends on several factors, such as the surface and the local weather. Appropriate predictions of wind speed in a specific area are necessary for wind power and energy estimations in that area. One of the models for characterizing the wind power is a cubic function of the wind speed. Therefore, a small error in the prediction of wind speed leads to huge variations in the wind energy estimation. Various methods are used to study the characteristics of wind speed. Weibull and Rayleigh distributions are the most preferred methods, as they are flexible and easy in terms of parameter determination.

The focus in this paper was on the Rayleigh distribution, which is a special form of the Weibull distribution with a shape factor that is always equal to two. In the Rayleigh distribution, the mean wind speed is sufficient to determine the wind characteristics. The Rayleigh distribution function $\left(f_{R}(v)\right)$ is given by Equation $(1)[20,21]$.

$$
f_{R}(v)=\left(\frac{\pi}{2}\right)\left(\frac{v}{v_{a}^{2}}\right) \exp -\left[\frac{\pi}{4}\left(\frac{v}{v_{a}}\right)^{2}\right]
$$

where $v_{a}$ is the average wind speed in a specific area in $(\mathrm{m} / \mathrm{s})$. The wind speed logarithmic law shown in Equation (2) was used to model the variation of wind speed due to the difference in height between the anemometers of the metrological station and the hub of the proposed wind turbine. In addition, it considered the terrain roughness between two altitudes [12,22].

$$
\frac{v}{v_{0}}=\frac{\ln \left(H / z_{0}\right)}{\ln \left(H_{0} / z_{0}\right)}
$$

where $v_{0}$ is the wind speed corresponding to the height $\left(H_{0}\right)$ and $Z_{0}$ is the roughness coefficient. A case study was conducted in Aqaba, which is the free Trade Area in Jordan. The wind speed was measured 
in a specific location using anemometer installed at $45 \mathrm{~m}$ above ground level, in which the output data was taken on a monthly average basis. Then, Rayleigh distribution was used to obtain hourly data, as shown in Figure 2. The roughness factor of the logarithm used for this case was 0.03 to adjust for the wind speed of open terrain areas [22]. Also, the hub height of the proposed wind turbine was $80 \mathrm{~m}$ (Table 2) which was also considered in the logarithm. The wind speed-based Rayleigh distribution function in Aqaba for twelve months is shown in Figure 2.

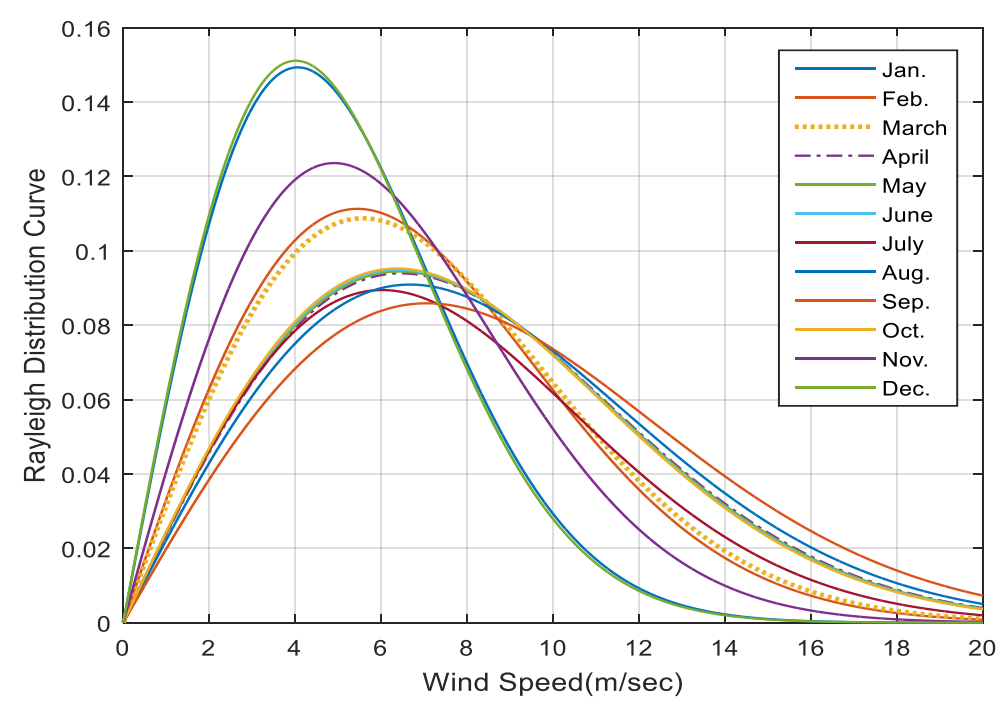

Figure 2. Curves of Rayleigh distribution for all months.

Table 2. Manufacturer information of a C96-2.5 MW wind turbine.

\begin{tabular}{|c|c|}
\hline \multicolumn{2}{|c|}{ Turbine } \\
\hline Manufacturer & USA \\
\hline \multicolumn{2}{|c|}{ Power } \\
\hline Rated power & $2.5 \mathrm{MW}$ \\
\hline Cut-in wind speed & $4.0 \mathrm{~m} / \mathrm{s}$ \\
\hline Rated wind speed & $12.5 \mathrm{~m} / \mathrm{s}$ \\
\hline Cut-out wind speed & $25.0 \mathrm{~m} / \mathrm{s}$ \\
\hline Survival wind speed & $70.0 \mathrm{~m} / \mathrm{s}$ \\
\hline \multicolumn{2}{|c|}{ Rotor } \\
\hline Diameter & $96.0 \mathrm{~m}$ \\
\hline Swept area & $7238 \mathrm{~m}^{2}$ \\
\hline Number of blades & 3 \\
\hline Maximum rotor speed & $15.5 \mathrm{U} / \mathrm{min}$ \\
\hline Tip speed & $78 \mathrm{~m} / \mathrm{s}$ \\
\hline Type & 46.7 \\
\hline Material & Fiberglass \\
\hline Power density & $345.4 \mathrm{~W} / \mathrm{m}^{2}$ \\
\hline \multicolumn{2}{|c|}{ Gearbox } \\
\hline Type & Spur \\
\hline Stages & 2.0 \\
\hline \multicolumn{2}{|c|}{ Tower } \\
\hline Hub height & $80.0 \mathrm{~m}$ \\
\hline Type & Steel tube \\
\hline Shape & conical \\
\hline Corrosion protection & painted \\
\hline
\end{tabular}


Other information that was determined for the wind farm to be precisely sized is shown in Table 3. The financial input parameters were the same as the ones described in the wind-only investigation [12]. The project lifetime was assumed to be 50 years. Therefore, the wind turbine will be replaced twice, with a cost that was assumed the same as the capital cost.

Table 3. Lifetime and spacing parameters of the wind farm.

\begin{tabular}{ccc}
\hline Parameter & Unit & Value \\
\hline Life-time per unit & Years & 20 \\
Row spacing of the farm (RS) & $\mathrm{m}$ & 384 \\
Column spacing of the farm (CS) & $\mathrm{m}$ & 672 \\
\hline
\end{tabular}

The geographical area of the wind farm $\left(A_{W F}\right)$ was computed using Equation (3). $L$ and $W$ are the dimensions of the wind farm, which was considered to have a rectangular shape. For the row spacing (RS) and column spacing (CS) values shown in Table 3, Equations (4) and (5) were used to calculate $L$ and $W$.

$$
\begin{gathered}
A_{W F}=L \times W \\
L=C_{S}\left(N_{\text {col }}-1\right)+D_{r} \\
W=R_{S}\left(N_{\text {row }}-1\right)+D_{r}
\end{gathered}
$$

where $D_{r}, N_{\text {row }}$, and $N_{\text {col }}$ are the rotor diameter, number of rows, and number of columns, respectively. These helped to compute the maximum and minimum wind areas, i.e., the $A_{\text {max }}$ and $A_{\text {min }}$. A footprint cap limit of 20,000 Dunam was considered for the on-grid wind hydro energy system.

\subsection{Load Demand Hourly Data}

The load demand hourly values of Aqaba, Jordan in 2017 were prepared after tailoring the supervisory control and data acquisition (SCADA) demand values in 2016 used in [12]. They were obtained from the National Control Center of the National Electric Power Company, Jordan. A percentage growth of $6 \%$ for a year is usually used in electric utilities in Jordan to obtain the annual load demand for the following year, therefore, in this paper, the hourly load values in 2017, as shown in Figure 3, were obtained by applying this percentage.

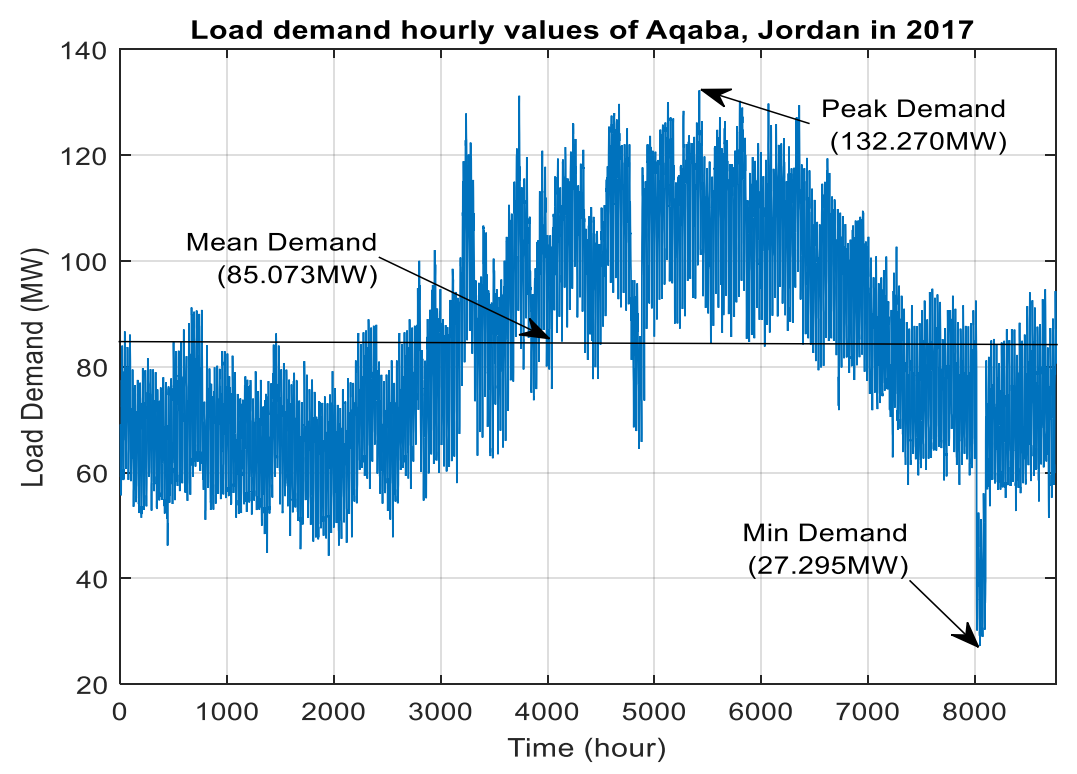

Figure 3. Load demand hourly values of the Aqaba Qasabah district in 2017. 
The minimum, maximum, and mean load demand values were $27.295 \mathrm{MW}, 132.270 \mathrm{MW}$, and 85.073 MW, respectively, as shown in Figure 3.

\section{Mathematical System Formulation}

\subsection{Modeling of the Hydro Station}

The priority was to satisfy the load from the wind farm. If the wind power was not sufficient, then energy deficit should be covered by the PHS station and, lastly, the energy purchased from the utility grid. The Matlab code had the target of satisfying the entire load. Three cases were considered. First, the load was satisfied by the wind farm, and if there was excess wind power and the reservoir was full, the generation of the hybrid renewable energy system came only from the wind power plant. Second, the load was satisfied by the wind farm, and there was excess wind power and the reservoir was not full. Thus, we computed the excess wind power that could charge the PHS plant by comparing the excess wind power value to the rated capacity of the PHS plant.

Third, when the generation of wind farm was less than what was required by the load demand, we checked the availability of the PHS plant for this power deficit. Moreover, the PHS minimum energy storage capacity was set, which was not exceeded during the discharge.

Once the rated power of the hydro station, $P_{\text {rated }}$, in $\mathrm{kW}$ was optimized, the energy in $\mathrm{kWh}, W_{\text {rated }}$, was estimated based on the assumption made in Section 2.1. Then, the potential energy (in $\left.\mathrm{J} / \mathrm{m}^{3}\right)$, $W_{J}$, and (in $\left.\mathrm{kWh} / \mathrm{m}^{3}\right), W_{k W h}$, of water in the upper reservoir were computed using Equation (6) and Equation (7), respectively.

$$
\begin{gathered}
W_{J}=\rho_{\text {water }} g H \\
W_{k W h}=2.78 \times 10^{-7} W_{J}
\end{gathered}
$$

where $\rho_{\text {water }}$ is the density of water $\left(1000 \mathrm{~kg} / \mathrm{m}^{3}\right), g$ is the gravitational acceleration $\left(9.81 \mathrm{~m} / \mathrm{s}^{2}\right)$, and $H$ is the actual head of the PHS station [12].

Then, the volume of the water in the upper reservoir $\left(\right.$ in $\left.\mathrm{m}^{3}\right), V_{\text {water, }}$ was computed using Equation (8). At this point, the area required for the PHS station, $A_{P H S}$, was computed using Equation (9) for a given mean depth, $D$ [12]. Furthermore, Equation (10) was used to compute the water flow $\left(F_{\text {water }}\right)$ in the pipeline in $\left(\mathrm{m}^{3} / \mathrm{s}\right)[23]$.

$$
\begin{aligned}
V_{\text {water }} & =\frac{E_{\text {rated }}}{\eta W_{k W h}} \\
A_{P H S} & =\frac{V_{\text {water }}}{D} \\
F_{\text {water }} & =\frac{P_{\text {rated }}}{\eta H g}
\end{aligned}
$$

\subsection{Modeling of the Wind Turbine Power Curve}

The wind turbine output power model can be typically presented in two main regions. Region 1 exists between the cut-in speed [1] and the rated wind speed $\left(V_{R}\right)$, while Region 2 exists between $V_{R}$ and the cut-out wind speed [6], as shown in Figure 4. This shows the ideal model representation of a wind turbine and the corresponding main regions.

To convert the hourly wind speed values, obtained before using Rayleigh distribution, into hourly output wind turbine values, the mathematical model in Equation (11) is used to model Region 1 shown in Figure 4. $P_{R}$ is the rated power generated by a wind turbine. Further, the corresponding A, B and C parameters are given in Equations (12)-(14) $[9,24,25]$. This model is different from the ones described in [12]. The output power in Region 1 runs smoothly between $V_{I}$ and $V_{R}$ with no protrusions at the cut-in value, as shown in the models described in [12], see Figure 5. This will result in an accurate computation of the output power extracted from the wind farm. This leads to precise computations in 
the output wind power and energy and thus in the number of units sizing, geographical footprint, economic and environmental indicators.

$$
\begin{gathered}
P(v)=\left\{\begin{array}{cc}
P_{R}\left(A+B v+C v^{2}\right), & V_{I} \leq v \leq V_{R} \\
P_{R}, & V_{R} \leq v \leq V_{o}
\end{array}\right\} \\
A=\frac{1}{\left(V_{I}-V_{R}\right)^{2}}\left[V_{I}\left(V_{I}+V_{R}\right)-4 V_{I} V_{R}\left(\frac{V_{I}+V_{R}}{2 V_{R}}\right)^{3}\right] \\
B=\frac{1}{\left(V_{I}-V_{R}\right)^{2}}\left[4\left(V_{I}+V_{R}\right)\left(\frac{V_{I}+V_{R}}{2 V_{R}}\right)^{3}-\left(3 V_{I}+V_{R}\right)\right] \\
C=\frac{1}{\left(V_{I}-V_{R}\right)^{2}}\left[2-4\left(\frac{V_{I}+V_{R}}{2 V_{R}}\right)^{3}\right]
\end{gathered}
$$

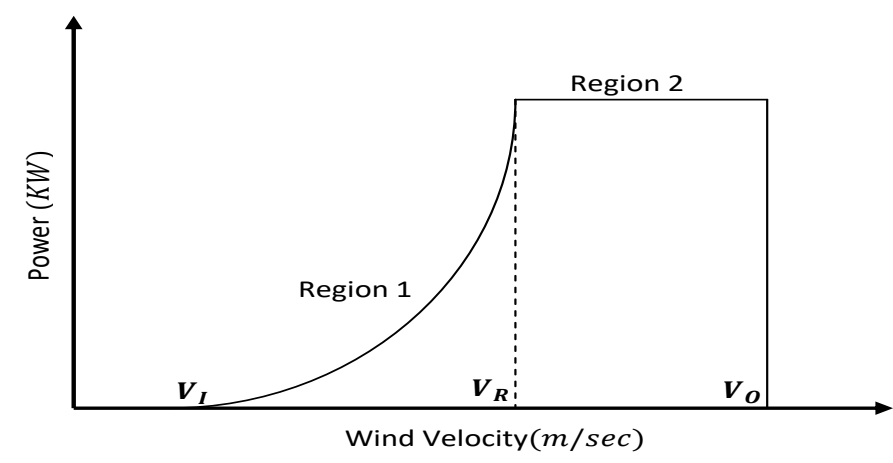

Figure 4. Schematic of wind turbine output power model.

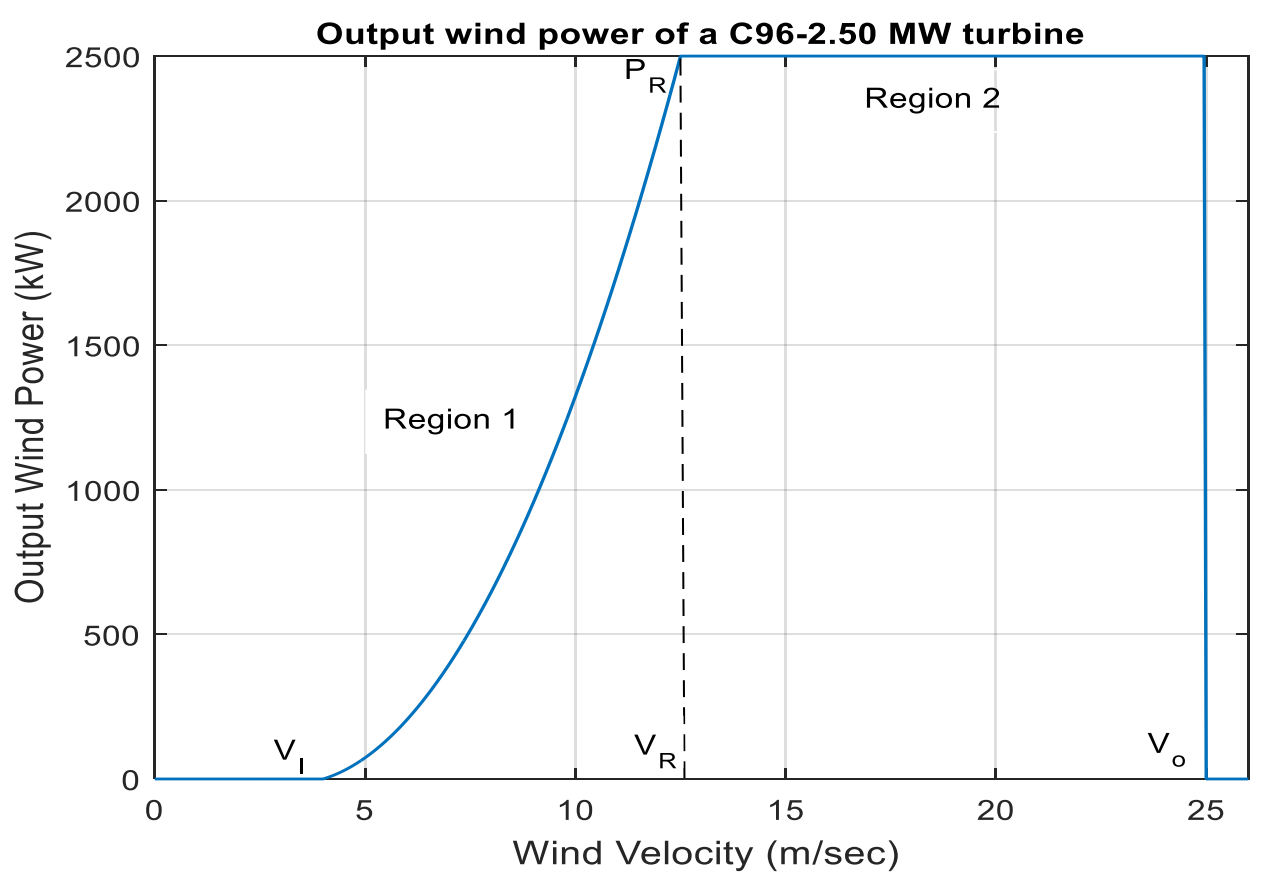

Figure 5. Output wind power of a C96-2.50 MW wind turbine.

\subsection{Objective Function}

The objective function in this study was selected to be the cost of energy of the penetrated system $\left(\mathrm{COE}_{\mathrm{PS}}\right)$ to reflect the price of the energy supplied by the on-grid hybrid wind hydropower system, as 
designed and sized to cover the load demand shown in Figure 3. It was computed by dividing the system's cost by the system's absorbed energy, as shown in Equation (15) [26].

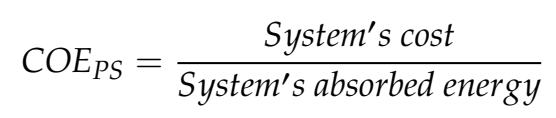

The system cost was computed by first constructing nominal and discounted cost cash flows for the project lifetime, i.e., 50 years. The nominal cash flow included the capital cost (CC), the replacement cost [22], the operation and maintenance cost (OMC), and the salvage cost (SC). These costs were discounted for the present in the discounted cash flow that represented the total current cost (TCC) of the renewable power system. The system cost calculation criteria are described in detail in [26]. The wind farm financial parameters are described in detail in [12]. The cost parameters of the PHS station are given in Table 1 . The cost of the energy from the utility grid had the last priority to satisfy the load demand.

Thus, an economic comparison with one hour time steps was done to satisfy the load demand in Figure 3. However, there were priorities built into the design code to satisfy the load demand; the wind farm first, then the PHS plant, and, lastly, the necessity to purchase energy from the grid if the load was still not satisfied. Moreover, the number of wind turbines (WTs) was computed based on the rated power, as shown Figure 5.

\subsection{Indicators of the Objective Function}

There are technical, economic, and environmental indicators that were computed based on the optimal value of the COE PS. These included the wind and hydro fraction $\left(W H_{f}\right)$, as shown in Equation (16), and carbon dioxide emissions $\left(\mathrm{E}_{\mathrm{CO} 2}\right)$.

$$
W H_{f}=\frac{\text { Renewable generation }}{\text { System's absorbed energy }}
$$

The $\mathrm{E}_{\mathrm{CO} 2}$ was computed by summing up the hourly multiplied grid energy purchases with a grid emission factor of $583.866667 \mathrm{gCO}_{2} / \mathrm{Wh}$.

\section{Optimization Toolbox of Matlab}

The optimization toolbox in Matlab is a collection of functions that implement Matlab's numerical capability and computing environment. This toolbox provides functions to find parameters which minimize or maximize objectives to satisfy specific constraints. Therefore, the optimal solutions of continuous and discrete problems can be obtained, tradeoff analyses can be achieved, and optimization design tasks can be performed using this toolbox. In addition, parameter estimations and tuning can be done using this toolbox. Moreover, solvers for linear programming (LP), quadratic programming, nonlinear programming (NLP), constrained linear least squares, nonlinear least squares, and nonlinear equations are included in this optimization tool box [27]. In this paper, the genetic algorithm (GA), simulated annealing (SA), and pattern search (PS) optimization methods were used from the Matlab toolbox.

GA, which is a search technique based on a principle of biological genetics and natural selection, allows a composition of many individuals to evolve under specified selection rules to a state that maximizes fitness under a specific objective function.

As a Matlab tool, GA is a powerful tool capable of providing robust approximation for systems that may be subject to uncertainties $[28,29]$. Its research mechanism consists of the use of candidate solutions represented in a binary form, called chromosomes. Several genetic operators, such as crossover, mutation, and inversion, are used to adapt and fit the generated population of chromosomes in each research step [29]. 
The flow of the genetic algorithm can be summarized by the following steps [30].

- Create initial population (usually a randomly generated string);

- Evaluate all the individuals (apply some function or formula to the individuals);

- Select a new population from the old population based on the fitness of the individuals and the required objective function;

- Apply some genetic operators (mutation, crossover, and inversion) to the population members to create new individuals;

- Evaluate the newly created individuals based on the required objective function.

Repeat the last three steps until the stopping criteria has been satisfied, where a certain fixed number of generations is obtained.

In summary, the GA toolbox has four main modules: The optimization problem definition module, the variables setting module, the generation of the initial population module, and the evolution module. These modules interact with each other by exchanging information that enables the operation of the algorithm. Before running the optimization algorithm, it is necessary to characterize the optimization problem. Then, the type and the representation of the variables used by the algorithm must be defined. GA works directly with real variables or with codified variables. Thus, depending on the type of variable defined by the problem and the type of representation used by the GA, there is a necessity for coding/decoding to pass from the actual workspace to the GA workspace.

Moreover, pattern search (PS), i.e., direct search or derivative-free search, is one of the Matlab optimization methods used to optimize functions that are not continuous or differentiable. Optimization attempts to find the best-match solution with the lowest error value in a multidimensional analysis space of possibilities [27]. Furthermore, simulated annealing (SA) is a Matlab toolbox method used to solve unconstrained and constrained optimization problems [31,32]. The models of this method simulate the heating process of the materials. At each iteration step of the simulated annealing algorithm, a new point is randomly generated. The distance of the new point from the current point is based on a probability distribution with a scale proportional to the temperature. An annealing schedule is selected to systematically decrease the temperature as the algorithm proceeds. As the temperature decreases, the algorithm extends its search to finally reach an optimal solution. The SA algorithm consists of two main options, namely, "AcceptanceFcn" and "TemperatureFcn". The first option accepts the worst case in order to achieve a global solution for the desired problem. The second option selects the suitable algorithm uses to update the temperature. Two stopping criteria are used for the SA algorithm, which are function tolerance and maximum iterations. In the first criterion, the algorithm runs until the average change in value of the objective function is less than the value of tolerance. In the second criterion, the maximum number of iterations can be determined [27].

\section{Results and Discussion}

Every component shown in Figure 1 was modeled and coded in Matlab along with the objective function of the cost of energy of penetrated system $\left(\mathrm{COE}_{\mathrm{PS}}\right)$ and the rest of the corresponding indicators. Table 4 shows the results obtained using the GA, SA, and PS solvers. Also, many data corresponding to the optimal value of the $\mathrm{COE}_{\mathrm{PS}}$ are included in Table 4 . The three aforementioned solvers of the Matlab optimization toolbox were selected to solve the problem described in this paper. The SA and PS solvers provided solutions that were $1.27634 \%$ and $1.98903 \%$ higher than the GA solution, respectively. Therefore, the GA solution was found to be feasible compared with the other solutions. 
Table 4. Detailed results of the optimized system using genetic algorithm (GA), simulated annealing (SA), and pattern search (PS) algorithms.

\begin{tabular}{|c|c|c|c|}
\hline Parameter & Value (GA) & Value (SA) & Value (PS) \\
\hline $\mathrm{COE}_{\mathrm{PS}}(\$ / \mathrm{kWh})$ & 0.0955388 & 0.0967582 & 0.0974391 \\
\hline $\mathrm{E}_{\mathrm{CO} 2}(\mathrm{kt} /$ year $)$ & 198.9044 & 204.5988 & 207.5809 \\
\hline $\mathrm{COE}_{\text {Renewables }}(\$ / \mathrm{kWh})$ & 0.0631 & 0.0637 & 0.0641 \\
\hline Number of WTs & 47 & 45 & 44 \\
\hline$A_{\max }\left(\mathrm{m}^{2}\right)$ & $9,676,800$ & $7,142,400$ & $8,506,368$ \\
\hline$A_{\max }($ Dunam $)$ & 9676.800 & 7142.400 & 8506.368 \\
\hline$A_{\min }\left(\mathrm{m}^{2}\right)$ & $6,856,704$ & $6,561,792$ & $6,266,880$ \\
\hline$A_{\min }($ Dunam $)$ & 6856.704 & 6561.762 & 6266.880 \\
\hline Total cost $(\mathrm{M} \$)$ & 441.3 & 426.37 & 419.44 \\
\hline $\mathrm{WH}_{\mathrm{f}}(\%)$ & 56.1427 & 54.3791 & 53.4641 \\
\hline Grid purchases cost (M\$) & 45.649 & 46.956 & 47.641 \\
\hline Grid energy purchases (GWh) & 340.67 & 350.42 & 355.53 \\
\hline$P_{\text {rated }}(\mathrm{PHS})(\mathrm{kW})$ & $18,118.5$ & $19,226.37$ & $20,039.45$ \\
\hline$E_{\text {rated }}(\mathrm{PHS})(\mathrm{kWh})$ & 181,185 & $192,263.7$ & $200,394.5$ \\
\hline$W_{J}\left(\mathrm{~J} / \mathrm{m}^{3}\right)$ & & $4.905 \times 10^{5}$ & \\
\hline$W_{k W h}\left(\mathrm{kWh} / \mathrm{m}^{3}\right)$ & & 0.136359 & \\
\hline$V_{\text {water }}\left(\mathrm{m}^{3}\right)$ & $1.56322 \times 10^{6}$ & $1.65880 \times 10^{6}$ & $1.72895 \times 10^{6}$ \\
\hline$A_{P H S}\left(\right.$ in $\left.\mathrm{m}^{2}\right)$ & $104,214.902$ & $110,586.803$ & $115,263.501$ \\
\hline$A_{P H S}$ (in Dunam) & 104.2149 & 110.5868 & 115.2635 \\
\hline$F_{\text {water }}\left(\mathrm{m}^{3} / \mathrm{s}\right)$ & 43.457 & 46.115 & 48.065 \\
\hline
\end{tabular}

The GA solution of 0.0955388 \$/kWh was economically feasible compared with the SA and PS $\mathrm{COE}_{\mathrm{PS}}$ values. The optimal value of the $\mathrm{COE}_{\mathrm{PS}}$, which was found using the GA, is shown in Figure 6. This value was $28.7 \%$ less than the energy bought from the conventional electric network, which is an excellent indication for the economic feasibility of this suggested configuration.

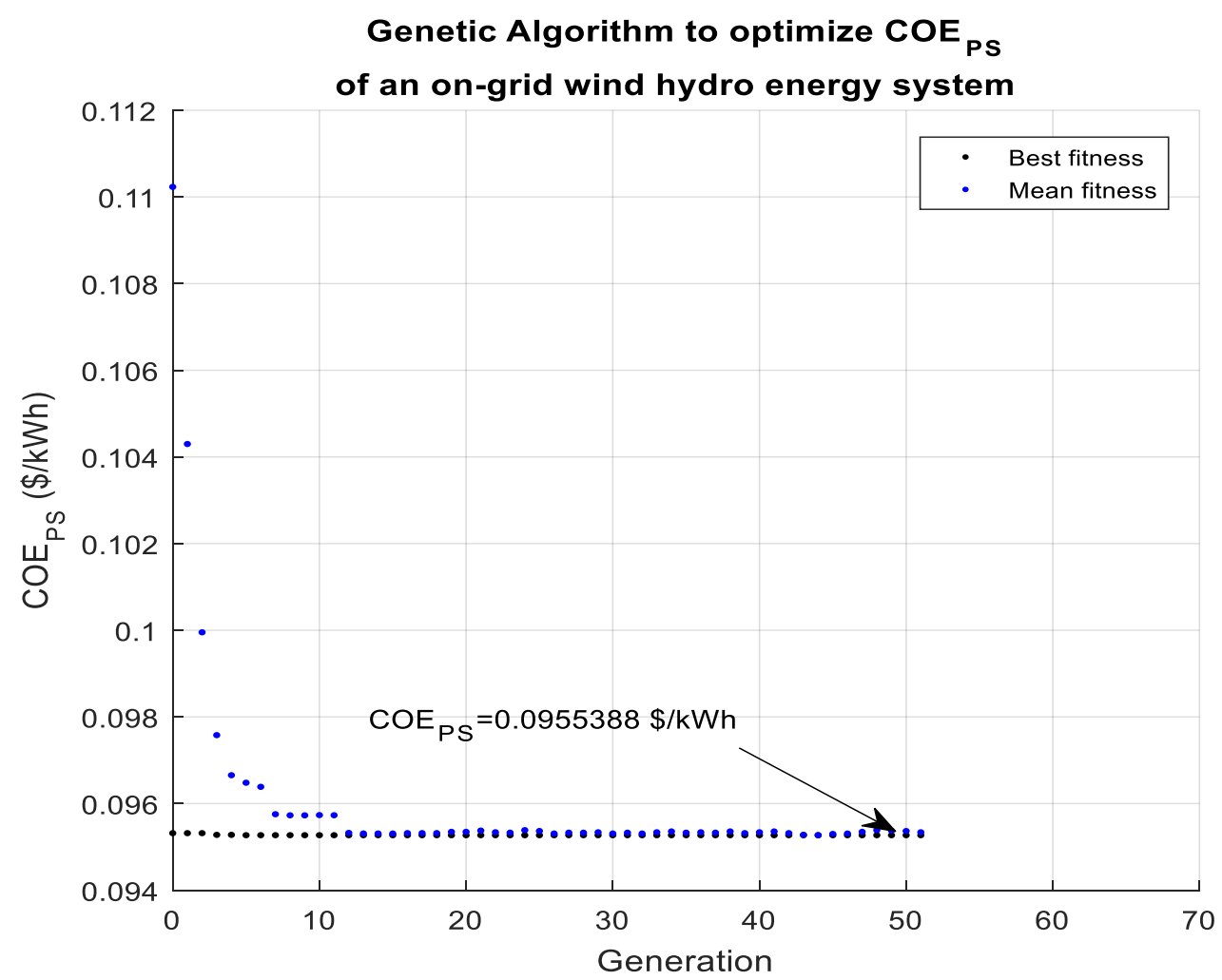

Figure 6. GA to optimize COEPS. 
Further, Figure 7 shows the current best point for the two decision variables found at the optimal value of the objective function.

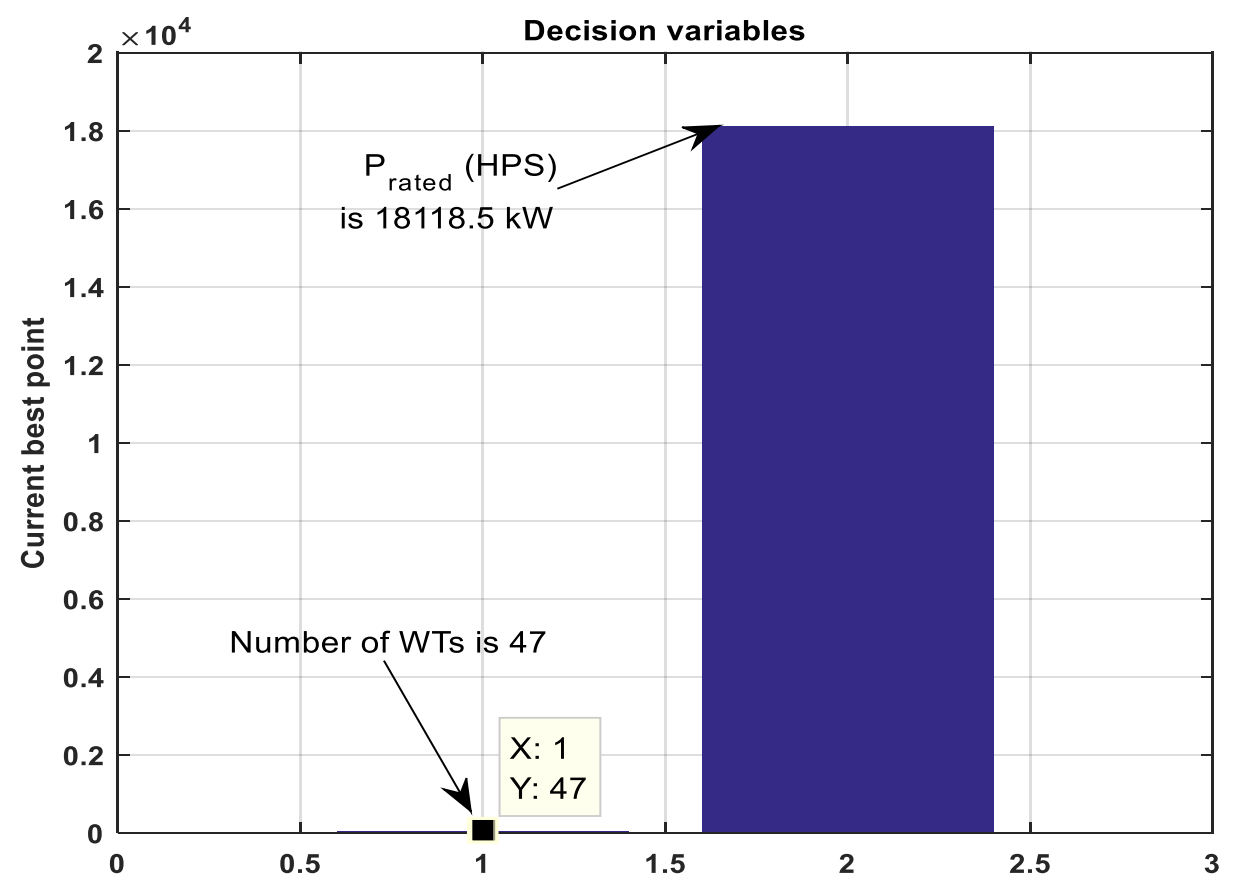

Figure 7. Corresponding decision variables of the optimal configuration.

Note that the area of the wind farm was assumed to be rectangular and was therefore computed by incrementing the odd optimal number by one. Furthermore, the $\mathrm{E}_{\mathrm{CO} 2}$ in the suggested location was $634.645 \mathrm{kt} /$ year [12], therefore, the emissions were mitigated by $68.66 \%$, assuming that the renewable configuration in Figure 1 was adopted. Also, the geographical area of renewable plants $\left(A_{\text {Renewables }}\right)$ was increased. However, only $48.91 \%$ of the geographical area limit was used to install the designed hydro-wind energy system. Thus, the rest of the area (51.09\%) could be used in the future as load demand and the system size grow.

The discounted payback period (DPP) is frequently used in renewable energy studies to find the length of time needed to retrieve the initial investment [33-35]. This was done in this paper by building the cumulative cash flow (CCF), as shown in Table 5. Note that the present value factor (PVF), cash flow $(\mathrm{CF})$, and the corresponding discounted cost values $\left(\mathrm{CF}_{\text {discounted }}\right)$ were calculated. The $\mathrm{CF}$ in Table 5 included the total cost found before in Table 4 using GA, and the energy savings of the renewable energy system. These energy savings were computed by multiplying the yearly renewable generation (436.438 GWh) by the energy purchased price of electric utilities in Jordan. Afterward, the CCF values were computed by cumulatively adding the discounted cost values. Then, the time to get back the total cost value was calculated using Equation (17). Note that Table 5 shows only 15 years of the 50-year project life-time, because the aim was to obtain a positive cost value from the CCF, which was held at the 11th year. This was just before the time when the total cost was retrieved. Table 5 shows that the DPP was computed to be around 10.271 years (10 years, 3 months, and 7 days).

$$
D P P=n_{l}+\frac{\left|C C F\left(n_{l}\right)\right|}{C F_{\text {discounted }}\left(n_{l}+1\right)}
$$

where $n_{l}$ is the year number at the last negative cost value of the CCF. 
Table 5. Calculation of the discounted payback period.

\begin{tabular}{ccccc}
\hline Year $\mathbf{( N )}$ & $\mathbf{P V F}$ & $\mathbf{C F} \mathbf{( M \$ )}$ & $\mathbf{C F}_{\text {discounted }} \mathbf{( M \$ )}$ & $\mathbf{C C F} \mathbf{( M \$ )}$ \\
\hline 0 & 1.000 & -441.300 & -441.300 & -441.300 \\
1 & 0.944 & 58.483 & 55.234 & -386.066 \\
2 & 0.892 & 58.483 & 52.165 & -333.901 \\
3 & 0.842 & 58.483 & 49.267 & -284.633 \\
4 & 0.796 & 58.483 & 46.530 & -238.103 \\
5 & 0.751 & 58.483 & 43.945 & -194.158 \\
6 & 0.710 & 58.483 & 41.504 & -152.654 \\
7 & 0.670 & 58.483 & 39.198 & -113.456 \\
8 & 0.633 & 58.483 & 37.020 & -76.436 \\
9 & 0.598 & 58.483 & 34.964 & -41.472 \\
10 & 0.565 & 58.483 & 33.021 & -8.451 \\
11 & 0.533 & 58.483 & 31.187 & 22.736 \\
12 & 0.504 & 58.483 & 29.454 & 52.190 \\
13 & 0.476 & 58.483 & 27.818 & 80.008 \\
14 & 0.449 & 58.483 & 26.272 & 106.280 \\
15 & 0.424 & 58.483 & 24.813 & 131.093 \\
\multicolumn{2}{c}{ DPP (Years) } & & 10.27096862 & \\
\hline
\end{tabular}

The study performed in this paper, after adding the hydro storage system, was compared to a previously studied scenario in [12] for a wind-only system connected to the utility grid at the same location. Table 6 shows the percentage increase/decrease for the parameters computed in Table 4 . For the wind-hydro on-grid system, the $\mathrm{COE}_{\mathrm{PS}}$ and the grid purchases were reduced by $16.93 \%$ and $24.68 \%$, respectively, showing the importance of the storage system for wind power that fluctuates naturally. These cost and emissions reductions are significant, especially for non-oil producing countries, such as Jordan, which imports around $96 \%$ of its energy needs as oil and natural gas. The carbon emissions reduction was improved compared with the wind-only system. Furthermore, renewable penetration increased by $56.64 \%$ as a result of adding the PHS system, resulting in a more environmentally friendly power system.

Table 6. On-grid wind farm with/without PHS comparison.

\begin{tabular}{cc}
\hline Parameter & Percentage Increase $(+)$ or Decrease $(-)$ in $\%$ \\
\hline $\mathrm{COE}_{\mathrm{PS}}$ & -12.26 \\
$\mathrm{E}_{\mathrm{CO} 2}$ & -24.69 \\
$\mathrm{COE}_{\text {Renewables }}$ & -1.52 \\
Number of WTs $_{A_{\text {Renewables }}(\max )}$ & +104.35 \\
$A_{\text {Renewables }}(\min )$ & +71.14 \\
Total cost & +21.79 \\
WH $_{\mathrm{f}}$ & +110.83 \\
Grid purchases cost & +56.64 \\
Grid energy purchases & -24.69 \\
\hline
\end{tabular}

\section{Conclusions}

In this paper, every component shown in Figure 1 was modeled and coded in Matlab along with the objective function (COE $\mathrm{CS}_{\mathrm{PS}}$. A wind-hydro grid connected power system was proposed as an adjunct to an existing power grid. This was mathematically modeled and then coded in Matlab. The GA of the Matlab optimization toolbox was used to find the optimal feasible value of the $\mathrm{COE}_{\mathrm{PS}}$, which was $0.0955388 \$ / \mathrm{kWh}$. This was $28.7 \%$ less than the conventional energy from the power grid. The discounted payback period was 10 years, 3 months, and 7 days. Furthermore, carbon emissions were reduced by $68.66 \%$ compared with experimentally estimated data. As a result, the grid energy purchases were also reduced. Specifically, comparing the system described in this study with the 
formerly studied on-grid wind-only system showed that the $\mathrm{COE}_{\mathrm{PS}}, \mathrm{E}_{\mathrm{CO} 2}, \mathrm{COE}_{\text {Renewables, }}$ and grid energy purchases were reduced by $12.26 \%, 24.69 \%, 1.52 \%$, and $24.68 \%$, respectively. These are very promising results, especially for oil-importing countries, such as Jordan, where imported energy is a significant financial burden to the economy. The proposed wind power system with hydro storage is recommendable for its clean and economical features, compared with the conventional fossil-fueled grid or wind-only on-grid renewable configurations.

Finally, this paper is a case study to demonstrate the important point of local solutions to the global problem of global warming. The paper is necessarily limited to the specific data and assumptions of the local case study. Future work will include applying the above principle and the methodology of this paper to many other local engineering boundary conditions.

Author Contributions: H.M.K.A.-M. wrote the paper, brought the measured data from formal institutions in Jordan, performed the simulation and optimization using Matlab optimization toolbox, mathematically modeled the system and coded these models in Matlab; M.E. helped obtain more meaningful results and reviewed the article before the final submission; A.A.-Q. reviewed the paper and performed the pdf distribution to convert the monthly average wind speed measured data into hourly data; A.A. reviewed the paper and wrote the literature review part.

Funding: This research received no external funding.

Acknowledgments: The authors would like to acknowledge Yarmouk University, Irbid, Jordan, for their support in this research.

Conflicts of Interest: The authors declare no conflict of interest.

\section{References}

1. Bostan, I.; Gheorghe, A.V.; Dulgheru, V.; Sobor, I.; Bostan, V.; Sochirean, A. Resilient Energy Systems: Renewables: Wind, Solar, Hydro; Springer Science \& Business Media: Berlin/Heidelberg, Germany, 2013; Volume 19.

2. Hammad, M.; Aburas, R.; Abuzahra, B. The potential of hydropower generation in Jordan. Energy Policy 1994, 22, 523-530. [CrossRef]

3. Wagner, H.-J.; Mathur, J. Introduction to Hydro Energy Systems: Basics, Technology and Operation; Springer Science \& Business Media: Berlin/Heidelberg, Germany, 2011.

4. Fritz, J.J. Small and Mini Hydropower Systems: Resource Assessment and Project Feasibility; McGraw-Hill: New York, NY, USA, 1984.

5. Kiran, B.D.H.; Kumari, M.S. Demand response and pumped hydro storage scheduling for balancing wind power uncertainties: A probabilistic unit commitment approach. Int. J. Electr. Power Energy Syst. 2016, 81, 114-122. [CrossRef]

6. Castronuovo, E.D.; Usaola, J.; Bessa, R.; Matos, M.; Costa, I.; Bremermann, L.; Lugaro, J.; Kariniotakis, G. An integrated approach for optimal coordination of wind power and hydro pumping storage. Wind Energy 2014, 17, 829-852. [CrossRef]

7. Foley, A.; Leahy, P.; Li, K.; McKeogh, E.; Morrison, A. A long-term analysis of pumped hydro storage to firm wind power. Appl. Energy 2015, 137, 638-648. [CrossRef]

8. Golshani, A.; Sun, W.; Zhou, Q.; Zheng, Q.P.; Wang, J.; Qiu, F. Coordination of Wind Farm and Pumped-Storage Hydro for a Self-healing Power Grid. IEEE Trans. Sustain. Energy 2018, 9, 1910-1920. [CrossRef]

9. Hozouri, M.A.; Abbaspour, A.; Fotuhi-Firuzabad, M.; Moeini-Aghtaie, M. On the use of pumped storage for wind energy maximization in transmission-constrained power systems. IEEE Trans. Power Syst. 2015, 30, 1017-1025. [CrossRef]

10. Portero, U.; Velázquez, S.; Carta, J.A. Sizing of a wind-hydro system using a reversible hydraulic facility with seawater. A case study in the Canary Islands. Energy Convers. Manag. 2015, 106, 1251-1263. [CrossRef]

11. Zhou, B.; Liu, S.; Lu, S.; Cao, X.; Zhao, W. Cost-benefit analysis of pumped hydro storage using improved probabilistic production simulation method. J. Eng. 2017, 2017, 2146-2151. [CrossRef]

12. Al-Masri, H.M.; AbuElrub, A.; Ehsani, M. Optimization and Layout of a Wind Farm Connected to a Power Distribution System. In Proceedings of the 2018 IEEE International Conference on Industrial Technology (ICIT 2018), Lyon, France, 20-22 February 2018; pp. 1049-1054.

13. Ackermann, T. Wind Power in Power Systems, 2nd ed.; John Wiley: Chichester, UK, 2012. 
14. Wei, Z.; Hongxing, Y.; Lin, L.; Zhaohong, F. Optimum Design of Hybrid Solar-wind-diesel Power Generation System Using Genetic Algorithm. Hkie Trans. 2007, 14, 82-89. [CrossRef]

15. Gupta, R.A.; Kumar, R.; Bansal, A.K. Economic analysis and design of stand-alone wind/photovoltaic hybrid energy system using Genetic algorithm. In Proceedings of the 2012 International Conference on Computing, Communication and Applications, Dindigul, India, 22-24 February 2012; pp. 1-6.

16. Zach, K.; Auer, H.; Lettner, G. Facilitating Energy Storage to Allow High Penetration of Intermittent Renewable Energy; Intelligent Energy Europe: Brussels, Belgium, 2012.

17. Schoenung, S. Energy Storage Systems Cost Update; SAND2011-2730; Sandia National Laboratory: Albuquerque, NM, USA, 2011.

18. Makarov, Y.V.; Du, P.; Kintner-Meyer, M.C.W.; Jin, C.; Illian, H.F. Sizing Energy Storage to Accommodate High Penetration of Variable Energy Resources. IEEE Trans. Sustain. Energy 2012, 3, 34-40. [CrossRef]

19. Rastler, D. Electricity Energy Storage Technology Options: A White Paper Primer on Applications, Costs and Benefits; Electric Power Research Institute: Palo Alto, CA, USA, 2010.

20. Al-Quraan, A.; Alrawashdeh, H. Correlated capacity factor strategy for yield maximization of wind turbine energy. In Proceedings of the 2018 5th International Conference on Renewable Energy: Generation and Applications (ICREGA), Al Ain, UAE, 25-28 February 2018; pp. 264-267.

21. Al-Quraan, A.A.; Pillay, P.; Stathopoulos, T. Use of a wind tunnel for urban wind power estimation. In Proceedings of the PES General Meeting Conference \& Exposition, National Harbor, MD, USA, 27-31 July 2014; pp. 1-5.

22. Bañuelos-Ruedas, F.; Angeles-Camacho, C.; Rios-Marcuello, S. Methodologies used in the extrapolation of wind speed data at different heights and its impact in the wind energy resource assessment in a region. In Wind Farm-Technical Regulations, Potential Estimation and Siting Assessment; InTech: Vienna, Austria, 2011.

23. Gatte, M.T.; Kadhim, R.A. Hydro power. In Energy Conservation; InTech: Vienna, Austria, 2012.

24. Park, G.L. Planning Manual for Utility Application of Wecs; Michigan State Univ., Div. of Engineering Research: East Lansing, MI, USA, 1979.

25. Billinton, R.; Chen, H.; Ghajar, R. A sequential simulation technique for adequacy evaluation of generating systems including wind energy. IEEE Trans. Energy Convers. 1996, 11, 728-734. [CrossRef]

26. Singh, S.; Kaushik, S.C. Optimal sizing of grid integrated hybrid PV-biomass energy system using artificial bee colony algorithm. IET Renew. Power Gener. 2016, 10, 642-650. [CrossRef]

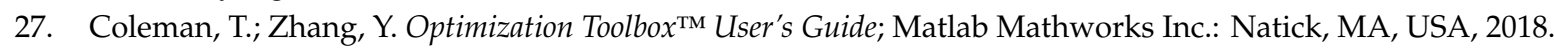

28. Haupt, R.L.; Haupt, S.E. Practical Genetic Algorithms, 2nd ed.; Wiley: Hoboken, NJ, USA, 2004.

29. Chaoui, H.; Khayamy, M.; Okoye, O.; Gualous, H. Simplified Speed Control of Permanent Magnet Synchronous Motors using Genetic Algorithms. IEEE Trans. Power Electron. 2018, 34, 3563-3574. [CrossRef]

30. Mohammadi, A.; Asadi, H.; Mohamed, S.; Nelson, K.; Nahavandi, S. Multiobjective and Interactive Genetic Algorithms for Weight Tuning of a Model Predictive Control-Based Motion Cueing Algorithm. IEEE Trans. Cybern. 2018, 49, 3471-3481. [CrossRef] [PubMed]

31. Ferreira, F.; Lemos, F. Unbalanced electrical distribution network reconfiguration using simulated anneling. In Proceedings of the 2010 IEEE/PES Transmission and Distribution Conference and Exposition: Latin America (T\&D-LA), Sao Paulo, Brazil, 8-10 November 2010; pp. 732-737.

32. Anantathanavit, M.; Munlin, M.-A. Fusing Binary Particle Swarm Optimzation with Simulated Annealing for Knapsack Problems. In Proceedings of the 2014 9th IEEE Conference on Industrial Electronics and Applications, Hangzhou, China, 9-11 June 2014; pp. 1995-2000.

33. Jan, I. Discounted Payback Period. Available online: https://bit.ly/2MuZPMP (accessed on 19 October 2019).

34. Gorshkov, A.; Vatin, N.; Rymkevich, P.; Kydrevich, O. Payback period of investments in energy saving. Mag. Civ. Eng. 2018, 78, 65-75.

35. Abuelrub, A.; Saadeh, O.; Al-Masri, H. Scenario aggregation-based grid-connected photovoltaic plant design. Sustainability 2018, 10, 1275. [CrossRef]

(C) 2019 by the authors. Licensee MDPI, Basel, Switzerland. This article is an open access article distributed under the terms and conditions of the Creative Commons Attribution (CC BY) license (http://creativecommons.org/licenses/by/4.0/). 